\title{
Erratum to: Sulforaphane inhibits growth of phenotypically different breast cancer cells
}

Anna Pawlik • Aleksandra Wiczk • Angelika Kaczyńska • Jędrzej Antosiewicz • Anna Herman-Antosiewicz

Published online: 21 March 2013

(c) Springer-Verlag Berlin Heidelberg 2013

\section{Erratum to: Eur J Nutr}

DOI 10.1007/s00394-013-0499-5

In the original publication, errors have been introduced during the typesetting processes which are corrected as given below.

In the "Abstract" and "Discussion" sections, phrases PI3K-AktmTOR-S6K1 or PI3K-Ak-tmTOR-S6K1 should correctly read PI3K-Akt-mTOR-S6K1.

The online version of the original article can be found under doi:10.1007/s00394-013-0499-5.

\footnotetext{
A. Pawlik · A. Wiczk · A. Kaczyńska ·

A. Herman-Antosiewicz $(\square)$

Department of Molecular Biology, University of Gdańsk,

Wita Stwosza 59, 80-308 Gdańsk, Poland

e-mail: wuzel@biotech.ug.gda.pl

J. Antosiewicz

Department of Bioenergetics and Physiology of Exercise,

Medical University of Gdańsk, Dębinki 1,

80-211 Gdańsk, Poland
} 